\title{
Association between endothelin-1 and fibromyalgia syndrome
}

\author{
SEONG-SU NAH ${ }^{1}$, HWAYOUNG LEE ${ }^{2}$, YEONGSEON HONG ${ }^{1}$, JIYUN IM $^{2}$, HANSOL WON ${ }^{2}$, \\ SUNG-HAE CHANG ${ }^{1}$, HYUNG-KI KIM ${ }^{2}$, JUN-TACK KWON ${ }^{2}$ and HAK-JAE KIM ${ }^{2,3}$ \\ ${ }^{1}$ Division of Rheumatology, Department of Internal Medicine; ${ }^{2}$ Department of Clinical Pharmacology; \\ ${ }^{3}$ Soonchunhyang Medical Research Institute, College of Medicine, Soonchunhyang University, \\ Cheonan, Chungcheongnam 31151, Republic of Korea
}

Received March 9, 2017; Accepted August 1, 2017

DOI: $10.3892 / \mathrm{mmr} .2017 .7395$

\begin{abstract}
Fibromyalgia syndrome (FMS) is characterized by widespread chronic musculoskeletal pain, stiffness and pressure hyperalgesia at soft tissue tender points. Patients with FMS may exhibit a tendency towards cold extremities and cold-induced vasospasm. Endothelin-1 (EDN1) is a potent vasoconstrictor that is mainly produced by endothelial cells. The present study aimed to determine whether plasma expression levels avvnd single-nucleotide polymorphism (SNP; rs1800541) of the EDN1 gene were associated with FMS and/or any of its clinical variables. Plasma EDN1 levels were assessed by ELISA, and SNP genotypes were determined using polymerase chain reaction-high-resolution melting curve analysis. Patients with the TG genotype and the $G$ allele may have an elevated risk of FMS. In addition, patients with FMS with the TG genotype and/or T allele exhibited higher plasma EDN1 levels compared with healthy controls. EDN1 levels increased significantly in patients with FMS compared with normal controls. In addition, EDN1 SNP was found to be associated with susceptibility to FMS.
\end{abstract}

\section{Introduction}

Fibromyalgia syndrome (FMS) is a complex disorder that is characterized by chronic widespread pain and muscle tenderness, and may be accompanied by disturbances in sleep, fatigue, anxiety and other clinical manifestations, such as depression, gastrointestinal symptoms and headache (1). FMS affects $\geq 2 \%$ of the adult population, with females significantly more affected than males (2). The etiology of FMS varies among subjects, but may include neurogenic inflammation caused by allergen-induced inflammatory response, bacterial

Correspondence to: Professor Hak-Jae Kim, Department of Clinical Pharmacology, College of Medicine, Soonchunhyang University, 31 Soonchunhyang 6 gil, Dongnamgu, Cheonan, Chungcheongnam 31151, Republic of Korea

E-mail: hak3962@sch.ac.kr

Key words: endothelin-1, plasma level, single-nucleotide polymorphism, fibromyalgia syndrome or viral infections, irritants or chemical exposure, as well as oxidative and emotional stressors $(3,4)$. Inflammation often includes increased levels of cytokines, neuropeptides, growth factors and neurotransmitters; however, many of these are abnormal in patients with FMS (5-7).

Although progress has been made in understanding the disease mechanism of FMS, its pathophysiology has not been clearly established. Genetic factors may influence susceptibility to FMS, but no specific gene has been identified. As FMS often occurs in several family members, there may be a genetic component. Several previous studies have reported candidate FMS polymorphisms, such as in the serotoninergic system genotype (8), the catechol-O-methyltransferase gene (9) and the D4 dopamine receptor (10). However, many of the previously identified associations have been weak or inconsistent.

Endothelin 1 (EDN1) is a peptide produced by endothelial and vascular smooth muscle cells and is a potent vasoconstrictor (11). Owing to the vasoconstrictive and hypertrophic actions on blood vessels, EDN1 has been linked to the development of hypertension (12). The human EDNl gene is $5.5 \mathrm{~kb}$ in length, with 5 exons and 4 introns (13). Patients with FMS express high levels of EDN1 $(14,15)$, have a high prevalence of insulin resistance (16) and may have increased body fat for a given weight (17). These data suggested that the EDN system may be activated in these patients, and the associations between EDN1 polymorphisms and EDN1 levels with the development of FMS may be more prominent compared with those in the general population. The prevalence of the EDN1 SNP rs1800541 and its association with EDN1 levels in patients with FMS has not yet been investigated. The T1370G single-nucleotide polymorphism (SNP; rs1800541) is in the EDN1 promoter region and may affect to EDN1 expression levels, which may be a potential intermediate hypertension phenotype (18).

The present study examined whether the rs1800541 SNP occurs more frequently in patients with FMS than in the local general population without FMS, and whether plasma EDN1 levels may be associated with susceptibility to FMS or the clinical variables.

\section{Materials and methods}

Subjects and clinical assessment. This study included a total of 88 patients with FMS (83 female and five male; age, 
$48.02 \pm 11.30$ years; weight, $58.63 \pm 0.99 \mathrm{~kg}$; mean \pm standard error of the mean) and 87 healthy controls (all female; age, $40.87 \pm 6.21$ years; weight, $57.17 \pm 0.84 \mathrm{~kg}$ ) without a history of FMS or chronic widespread pain (19). Collected data also included height and weight measurements that were used to assess body mass index (BMI). Biospecimens used by the present study were provided by the Biobank of the College of Medicine, Soonchunhyang University (Cheonan, Korea). This study was approved by the Ethics Review Committee of the Biobank of the College of Medicine, Soonchunhyang University (SCHIRB-BIO-150006); written informed consent was received from all patients prior to the study.

Clinical assessment. The presence of tender points was assessed according to the standardized manual tender point survey (20). The number of tender points was counted at 18 specific sites on the body, and the intensity of each tender point was assessed as follows: 0, no tenderness; 1, light tenderness (confirmed answer when asked); 2, moderate tenderness (spontaneous verbal response); and 3, severe tenderness (moving away). Therefore, the possible number of tender points ranged between 0 and 18, and the possible total score ranged between 0 and 54. Clinical disease activity and severity of FMS were assessed using various tools to diagnose FMS. The Korean version of the Fibromyalgia Impact Questionnaire (FIQ) was used to assess functional abilities (21); the Brief Fatigue Inventory (BFI) was used to assess fatigue severity (22); the Beck Depression Inventory (BDI) was used to assess depression severity (23); the Medical Outcomes Study 36-item Short-Form Health Survey, which comprises eight items, including physical health (physical functioning, role-physical, bodily pain and general health) and mental health (vitality, social functioning, role-emotional and mental health) (24), was used to assess quality of life; and the State-Trait Anxiety Inventory (STAI)-1 and STAI-2 was used to assess anxiety (Tables I and II) (25).

Measurement of plasma EDN1 levels. Plasma was extracted from fresh whole blood samples with EDTA. The blood was centrifuged at $13,200 \mathrm{x} \mathrm{g}$ for $10 \mathrm{~min}$ and stored at $-80^{\circ} \mathrm{C}$. Plasma EDN1 levels were determined using an Endothelin ELISA kit (cat no. 583151; Cayman Chemical, Ann Arbor, MI, USA) with $50 \mu 1$ plasma from each subject, according to the manufacturer's protocol.

Genotyping. DNA was extracted from fresh whole-blood samples $(300 \mu \mathrm{l})$ using a DNA purification kit (Nanohelix Co., Ltd., Seoul, Korea), according to the manufacturer's protocol. SNPs were identified by polymerase chain reaction-high-resolution melting (PCR-HRM) curve analysis and the SensiFAST HRM Kit (Bioline, Taunton, MA, USA) as previously described (26). The EDN1 gene primers were: Forward, 5'-CAGAATGACCCGGTGACACT-3' and reverse, 5'-CATTGGCTTTTTCCGCTAGT-3'. Cycling conditions were as follows: Activation of polymerase at $95^{\circ} \mathrm{C}$ for $2 \mathrm{~min}$; followed by 43 cycles of $95^{\circ} \mathrm{C}$ for $5 \mathrm{sec}, 60^{\circ} \mathrm{C}$ for $10 \mathrm{sec}$ and $72^{\circ} \mathrm{C}$ for $15 \mathrm{sec}$; and the HRM step at $95^{\circ} \mathrm{C}$ for $15 \mathrm{sec} ; 55^{\circ} \mathrm{C}$ for $15 \mathrm{sec}$; and $95^{\circ} \mathrm{C}$ for $5 \mathrm{sec}$.

Statistical analysis. Hardy-Weinberg equilibrium (HWE) was assessed using SNP Stats (http://bioinfo.iconcologia.
Table I. Clinical features of FMS and control groups.

\begin{tabular}{lcccccc}
\hline & \multicolumn{2}{c}{ Control $(\mathrm{n}=87)$} & & \multicolumn{2}{c}{ FMS $(\mathrm{n}=88)$} & \\
\cline { 2 - 3 } Parameter & Mean & SE & & Mean & SE & P-value \\
\hline Age & 40.87 & 0.67 & 48.02 & 1.20 & N/A \\
Male, n (\%) & $0(0.00)$ & & $5(5.68)$ & & N/A \\
Female, n $(\%)$ & $87(100.00)$ & & $83(94.32)$ & & \\
FIQ & 0.00 & 0.00 & 59.03 & 1.98 & $<0.001$ \\
BFI & 23.36 & 1.66 & 51.92 & 2.14 & $<0.001$ \\
BDI & 27.38 & 0.61 & 40.05 & 1.18 & $<0.001$ \\
PCS & 76.44 & 1.44 & 45.42 & 0.19 & $<0.001$ \\
MCS & 75.22 & 1.49 & 50.33 & 2.31 & $<0.001$ \\
STAI1 & 44.21 & 0.70 & 42.45 & 0.71 & 0.081 \\
STAI2 & 45.24 & 0.69 & 49.31 & 0.74 & $<0.001$ \\
\hline
\end{tabular}

FMS, fibromyalgia syndrome; N/A, not applicable; FIQ, fibromyalgia impact questionnaire; BFI, brief fatigue inventory; BDI, Beck depression inventory; PCS, physical component summary; MCS, mental component summary; STAI, State-Trait Anxiety Inventory.

net/index.php) and SPSS 18.0 software (SPSS Inc., Chicago, IL, USA). Associations between the SNP and patients with FMS were estimated by computing odds ratios (ORs) and 95\% confidence intervals (CIs) by logistic regression analyses with age and sex controlled as covariates. Models assuming co-dominant (where relative disease hazard differs between subjects with one minor allele and those with two minor alleles), dominant (subjects with one or two minor alleles demonstrate the same relative hazard), recessive (individuals with two minor alleles are at increased risk of the disease), or over-dominant inheritance (assumes the heterozygote has the strongest impact and compares major alleles/major alleles + minor alleles/minor allele vs. major alleles/minor allele) were used in the logistic regression analysis for the SNP. Genotypic and allelic frequencies of the SNP were compared between the patients with FMS and controls using the $\chi^{2}$ test for the case-control association study. The difference between patients with FMS and controls was adjusted for age and sex as covariables. $\mathrm{P}<0.05$ was considered to indicate a statistically significant difference.

\section{Results}

The relationship between the SNP and the clinical features of patients with FMS was assessed, including number of tender points, FIQ, BFI, BDI, STAI-I and STAI-II scores (Tables I and II). Most of the parameters were significantly different between the control and FMS group (Table I). None of the parameters assessed in the patients with FMS differed among the SNP genotypes or alleles (Table II).

The EDN1 SNP T1370G genotype was detected successfully by PCR-HRM analysis in all subjects $(n=175,100 \%)$. Distribution of the EDN1 T1370G genotype was consistent with HWE in the control and FMS subjects ( $\mathrm{P}>0.05)$. In total, 88 patients with FMS (age, $48.02 \pm 11.30$ years) were genotyped, of whom $83(94.3 \%)$ were female. A total of 87 healthy control 
Table II. Clinical assessments by genotype and allele in patients with FMS.

\begin{tabular}{|c|c|c|c|c|c|c|c|}
\hline \multirow[b]{2}{*}{ Assessment } & \multicolumn{4}{|c|}{ FMS genotype/allele } & \multicolumn{3}{|c|}{ Genotype/allele } \\
\hline & $\mathrm{TT}$ & $\mathrm{TG}$ & GG & P-value & $\mathrm{T}$ & $\mathrm{G}$ & P-value \\
\hline $\mathrm{n}$ & 35 & 40 & 13 & & 110 & 66 & \\
\hline FIQ & $61.06 \pm 2.85$ & $56.80 \pm 3.26$ & $60.42 \pm 4.75$ & 0.593 & $59.51 \pm 1.74$ & $58.23 \pm 2.36$ & 0.663 \\
\hline BFI & $55.29 \pm 3.25$ & $49.80 \pm 3.12$ & $49.38 \pm 6.55$ & 0.447 & $53.29 \pm 1.85$ & $49.64 \pm 2.58$ & 0.252 \\
\hline BDI & $39.03 \pm 1.77$ & $40.68 \pm 1.70$ & $40.85 \pm 3.87$ & 0.785 & $39.63 \pm 1.00$ & $40.74 \pm 1.46$ & 0.531 \\
\hline PCS & $45.52 \pm 2.72$ & $46.90 \pm 2.97$ & $40.64 \pm 5.86$ & 0.559 & $46.02 \pm 1.62$ & $44.43 \pm 2.42$ & 0.586 \\
\hline MCS & $47.95 \pm 3.44$ & $52.83 \pm 3.29$ & $49.05 \pm 7.77$ & 0.612 & $49.72 \pm 1.95$ & $51.34 \pm 2.89$ & 0.644 \\
\hline STAI1 & $43.31 \pm 1.11$ & $42.80 \pm 1.05$ & $39.08 \pm 1.79$ & 0.133 & $43.13 \pm 0.62$ & $41.33 \pm 0.83$ & 0.086 \\
\hline STAI2 & $48.47 \pm 1.11$ & $50.23 \pm 1.10$ & $48.69 \pm 2.26$ & 0.526 & $49.12 \pm 0.64$ & $49.62 \pm 0.90$ & 0.652 \\
\hline Tender points & $17.34 \pm 0.22$ & $16.60 \pm 0.40$ & $17.62 \pm 0.21$ & 0.139 & $17.00 \pm 0.26$ & $17.07 \pm 0.18$ & 0.817 \\
\hline Total score & $29.77 \pm 1.19$ & $27.70 \pm 1.26$ & $27.85 \pm 1.52$ & 0.442 & $27.76 \pm 0.86$ & $29.02 \pm 0.70$ & 0.259 \\
\hline
\end{tabular}

Data are presented as the mean \pm standard error of the mean; unclear or missing data have been excluded. FMS, fibromyalgia syndrome; FIQ, fibromyalgia impact questionnaire; BFI, brief fatigue inventory; BDI, Beck depression inventory; PCS, physical component summary; MCS, mental component summary; STAI, State-Trait Anxiety Inventory.

Table III. Genotype and allele frequencies of endothelin 1 single-nucleotide polymorphisms in healthy control patients and patients with fibromyalgia syndrome.

\begin{tabular}{|c|c|c|c|c|c|c|c|}
\hline \multirow[b]{2}{*}{ Genotype/allele } & \multicolumn{2}{|c|}{ Control (n=87) } & \multicolumn{2}{|c|}{ FMS (n=88) } & \multirow[b]{2}{*}{ Model } & \multirow[b]{2}{*}{ OR $(95 \% \mathrm{CI})$} & \multirow[b]{2}{*}{ P-value } \\
\hline & Freq. & $\%$ & Freq. & $\%$ & & & \\
\hline TT & 55 & 63.20 & 35 & 39.80 & Co-dominant & $3.14(1.59-6.23)$ & 0.004 \\
\hline TG & 20 & 23.00 & 40 & 45.50 & & $1.70(0.70-4.15)$ & \\
\hline \multirow[t]{3}{*}{ GG } & 12 & 13.80 & 13 & 14.80 & Dominant & $2.60(1.41-4.79)$ & 0.002 \\
\hline & & & & & Recessive & $1.08(0.46-2.53)$ & 0.850 \\
\hline & & & & & Overdominant & $2.79(1.45-5.36)$ & 0.002 \\
\hline $\mathrm{T}$ & 130 & 0.75 & 110 & 0.62 & & & \\
\hline G & 44 & 0.25 & 66 & 0.38 & & $0.56(0.36-0.89)$ & 0.014 \\
\hline
\end{tabular}

Freq, frequency; OR, odds ratio; CI, confidence intervals.

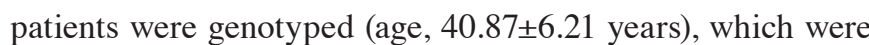
significantly younger compared with the patients with FMS, and which were all female; therefore, all results were adjusted for age and sex. The average body weight in the patients with FMS was $58.63 \pm 0.99 \mathrm{~kg}$, and in the control group was $57.17 \pm 0.84 \mathrm{~kg}$, which was not significantly different $(\mathrm{P}=0.260)$. The average BMI of the subjects was $23.33 \pm 0.36$ (FMS) and $22.17 \pm 0.43$ (control), which was slightly different $(\mathrm{P}=0.040)$; however, the BMI score was not identified as related to FMS genotype and plasma EDN1 levels.

Of the patients with FMS, 35 out of $88(39.80 \%)$ had the TT genotype, $40(45.50 \%)$ had TG and 13 (14.80\%) had the GG genotype of the EDN1 SNP. TG and GG genotype frequencies were 23.00 and $13.80 \%$ in the control group and 45.50 and $14.80 \%$ in the FMS group for the co-dominant model (OR, 3.14 and $1.70 ; 95 \%$ CI, 1.59-6.23 and 0.70-4.15, respectively; $\mathrm{P}=0.004$; Table III), respectively. The GG genotype was associated with an increased risk for FMS. FMS susceptibility was significantly associated in the over-dominant model ( $\mathrm{TG}+\mathrm{GG}$ vs. TT; OR, 2.79; 95\% CI, 1.45-5.36; P=0.002; Table III), indicating that absence of the $\mathrm{G}$ allele (TT) decreased the risk for FMS compared with the presence of the G allele (GG or TG). Allelic frequency was also associated with susceptibility to FMS (OR, 0.56; 95\% CI, 0.36-0.89; $\mathrm{P}=0.014$; Table III). The $\mathrm{T}$ allele frequency was lower in the FMS group $(62.0 \%)$ compared with in the control group $(75.0 \%)$.

Association between EDN1 gene polymorphisms and plasma EDN1 levels in healthy control patients and patients with FMS. Plasma EDN1 levels increased significantly in patients with FMS compared with patients in the control group (mean \pm standard error of the mean; $38.89 \pm 5.87$ vs. $61.34 \pm 8.14 \mathrm{pg} / \mathrm{ml} ; \mathrm{P}=0.027$; Fig. 1). Plasma EDN1 levels increased significantly in patients with the GG genotype $(83.30 \pm 21.93 \mathrm{pg} / \mathrm{ml})$ compared with those with the TG genotype $(53.91 \pm 10.04 \mathrm{pg} / \mathrm{ml})$ or TT genotype $(38.50 \pm 3.56 \mathrm{pg} / \mathrm{ml}$; 
$\mathrm{P}=0.011$; Fig. 2) in all patients. Plasma EDN1 levels in the $\mathrm{G}$ allele group $(67.27 \pm 8.93 \mathrm{pg} / \mathrm{ml})$ was relatively higher than that in the $\mathrm{T}$ allele group $(42.35 \pm 3.15 \mathrm{pg} / \mathrm{ml})$ among all patients (P<0.05; Fig. 3).

The relationship between plasma EDN1 level and EDN1 polymorphism was further compared within the patients. Plasma EDN1 levels in patients with FMS with the TG genotype were significantly higher compared with EDN1 levels in healthy control patients with the TG genotype $(68.32 \pm 14.41$ vs. $25.08 \pm 4.51 \mathrm{pg} / \mathrm{ml} ; \mathrm{P}=0.006$; Fig. $4 \mathrm{~A})$. In addition, the level of T-carrier group (TT + TG) in FMS patients was significantly higher compared with healthy controls (57.45 \pm 8.05 vs. $31.87 \pm 3.85 \mathrm{pg} / \mathrm{ml}$; P=0.002; Fig. 4B). It was also demonstrated that patients with FMS with the $\mathrm{T}$ allele exhibited higher levels of EDN1 in the plasma compared with healthy controls (53.50 \pm 5.70 vs. $32.91 \pm 3.05$ pg/ml; $\mathrm{P}=0.002$; Fig. 5). However, the levels of EDN1 expression were not significantly different between controls and FMS patients with $\mathrm{G}$ allele $(\mathrm{P}>0.05)$.

\section{Discussion}

The present study investigated the association between plasma EDN1 expression levels and the EDN1 SNP in patients with FMS. Genotypic and allelic distributions of EDN1 SNP in patients with FMS were significantly different from those in the healthy control patient group, which suggested an association between EDN1 SNP and FMS. In addition, plasma EDN1 levels in patients with FMS were demonstrated to be higher than those of healthy controls.

Vascular endothelial cells are able to modulate local vascular tone by secreting relaxing factors, such as nitric oxide, and constrictive factors such as EDN1. Other than its direct vasoconstrictive effect, EDN1 may also increase the sensitivity of blood vessels to other circulating vasoconstrictive hormones, including noradrenaline, serotonin and angiotensin II (27). EDN1 expression was previously demonstrated to be increased in certain vascular beds, such as in the heart (28) and the kidney (29), following tissue ischemia. Increased EDN1 production has also been described in other vascular and rheumatologic diseases, including vasospastic syndrome, multiple sclerosis, giant cell arteries and systemic lupus erythematosus $(30,31)$. It has been reported that patients with FMS have significantly higher levels of brachial-ankle pulse-wave velocity (baPWV) compared with healthy controls (32). BaPWV is correlated with disease severity assessed by FIQ (32). Another study reported that plasma EDN1 levels in German patients with FMS were significantly higher compared with those in healthy controls ( $n=21 /$ group) (31). The present study analyzed plasma EDN1 expression levels and SNPs to validate these results in a relatively large Korean population ( $\mathrm{n}=175$ total), and demonstrated that plasma EDN1 expression levels were increased in patients with FMS. In addition, subjects with $\mathrm{G}$ allele had higher EDN1 levels compared with $\mathrm{T}$ allele. Previous studies suggested a possible effect of EDN1 in distinctive vascular cold-response of patients with FMS $(33,34)$, in which repeated relative ischemia might increase EDN1 level. An elevated EDN1 level, in turn, may further enhance vasospasms.

Elevated tissue or plasma concentrations of EDN1 may occur in a variety of pathological states, such as metastasized

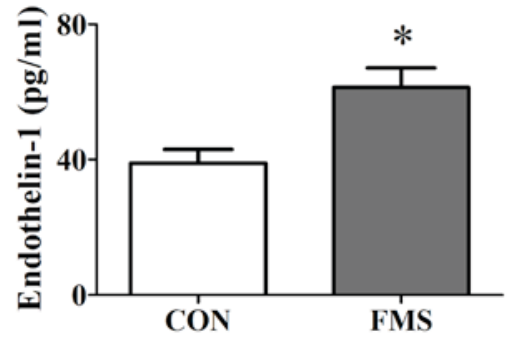

Figure 1. Comparison of plasma endothelin 1 levels between patients with FMS and healthy control patients. Plasma endothelin 1 levels in patients with FMS $(n=88)$ compared with the levels in healthy control patients $(n=87)$, as determined by ELISA. Data are presented as the mean \pm standard error of the mean. ${ }^{*} \mathrm{P}<0.05$ vs. CON. CON, control; FMS, fibromyalgia syndrome.

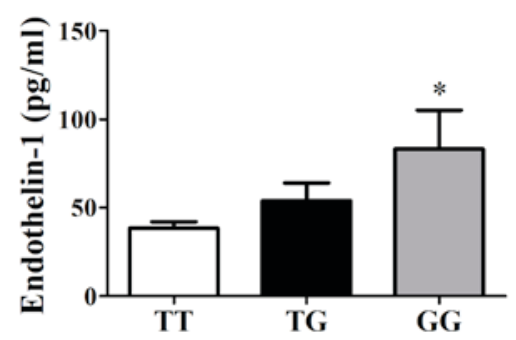

Figure 2. Plasma EDN1 expression levels in all patients containing TT, TG and GG of the EDN1 gene. The expression levels containing TT $(\mathrm{n}=90), \mathrm{TG}(\mathrm{n}=60)$ and $\mathrm{GG}(\mathrm{n}=25)$ of the EDN1 gene, as determined by ELISA. Data are presented as the mean \pm standard error of the mean. ${ }^{\mathrm{P}}<0.05$ vs. TG or TT. EDN1, endothelin-1.

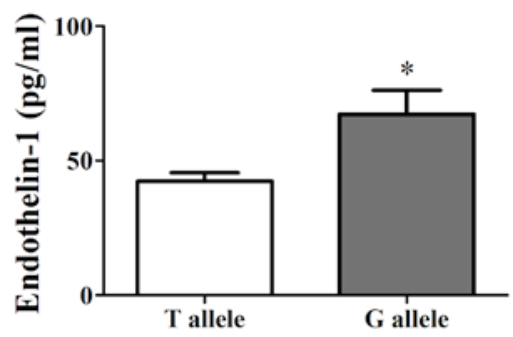

Figure 3. Plasma EDN1 levels in patients with FMS and controls containing the $\mathrm{T}(\mathrm{n}=240)$ or $\mathrm{G}$ alleles $(\mathrm{n}=110)$ of the EDN1 gene, as determined by ELISA. Data are presented as the mean \pm standard error of the mean. ${ }^{*} \mathrm{P}<0.05$ vs. T allele. EDN1, endothelin-1; FMS, fibromyalgia syndrome.

prostate and breast cancer cells (35), following cutaneous injury (36). Plasma EDN1 levels may also increase following ischemic injury related to acute respiratory distress syndrome, sepsis and disseminated intravascular coagulation $(37,38)$. EDN1 expression contributes to pain in many of these pathologies; inflammation leads to the release of substances that may excite or sensitize primary afferent nerve fibers and cause pain and/or hyperalgesia $(39,40)$, and EDN1 has been reported to be significantly oversecreted in inflammatory conditions (41). EDN1 levels in synovial fluid are elevated in patients with inflammation-related diseases, such as rheumatoid arthritis (RA), osteoarthritis and gout. Plasma EDN1 levels in patients with active RA were demonstrated to be higher than the levels in patients with non-active RA, whereas EDN1-like immunoreactivity in synovial fluid was revealed to be several-fold higher than in plasma (42). 
A

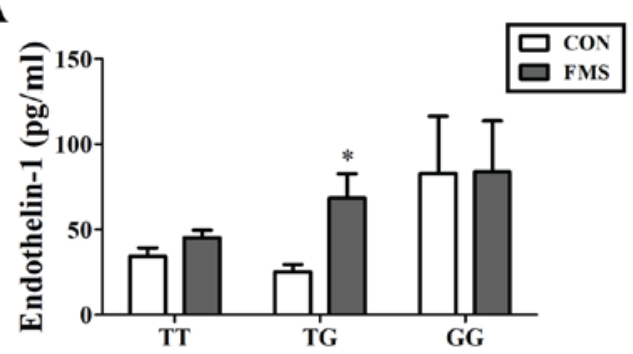

B

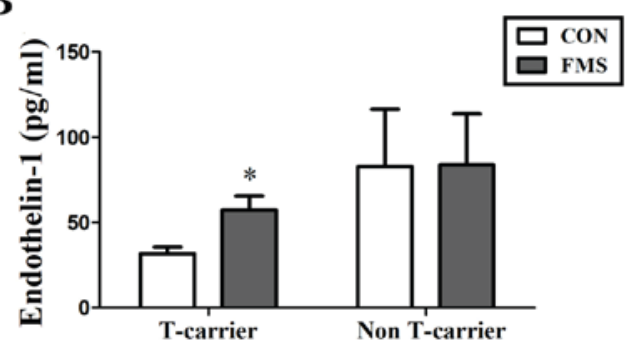

Figure 4. Plasma EDN1 levels and genotypes of EDN1 in the healthy control patients and patients with FMS. (A) EDN1 levels in control with the genotypes TT (n=55), TG (n=20), and GG (n=12) and FMS patients with EDN1 genotypes TT (n=35), TG (n=40), and GG (n=13) were determined by ELISA. (B) EDN1 levels in T-carrier control patients (TT + TG; $n=130)$ and non-T-carrier controls (GG; $n=44)$, and T-carrier patients with FMS (n=110) and non-T-carrier patients with FMS ( $\mathrm{N}=66)$ were determined by ELISA. Data are presented as the mean \pm standard error of the mean. $\mathrm{P}<0.05$ vs. CON. CON, control; EDN1, endothelin-1; FMS, fibromyalgia syndrome.

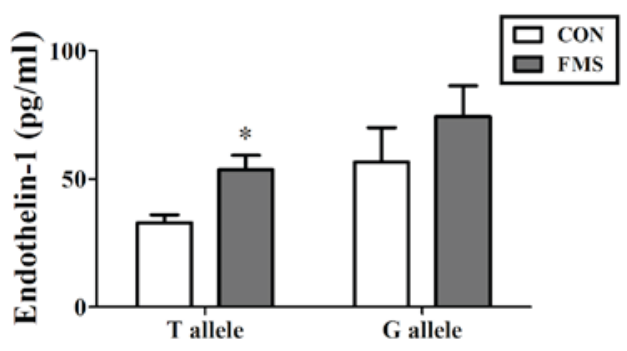

Figure 5. Plasma EDN1 levels and alleles of EDN1 in healthy control patients and patients with FMS. Plasma levels of EDN1 in the control group with T allele $(n=130)$ or $\mathrm{G}$ allele $(\mathrm{n}=44)$ and in FMS patients with $\mathrm{T}$ allele genotype $(n=110)$ or $\mathrm{G}$ allele genotype $(n=66)$ were determined by ELISA. Data are presented as the mean \pm standard error of the mean. ${ }^{*} \mathrm{P}<0.05$ vs. CON. CON, control; EDN1, endothelin-1; FMS, fibromyalgia syndrome.

Endothelial dysfunction may induce vascular inflammation by producing vasoconstricting agents, adhesion molecules and growth factors $(43,44)$. Patients with cardiovascular disease exhibit increased tissue expression and plasma levels of inflammatory markers and mediators, including C-reactive protein (CRP) and adhesion molecules, such as intercellular adhesion molecule 1 (ICAM1), selectins and vascular cell adhesion molecule 1 (VCAM1) $(45,46)$. In addition, patients with hypertension have been reported to exhibit increased plasma concentrations of tumor necrosis factor- $\alpha$ (a primary inflammatory cytokine), interleukin 6 (a secondary inflammatory cytokine), ICAM1, VCAM1, selectin E, von Willebrand factor and CRP (47). However, high concentrations of inflammatory mediators may be independent risk factors for the development of hypertension $(48,49)$. Additional studies are required to clarify the relationship between elevated plasma EDN1 levels and the aforementioned markers of vascular inflammation in patients with FMS to draw definite conclusions.

Results from the present study suggested that EDN1 may have a potential effect on disease susceptibility in patients with FMS. However, whether high EDN1 plasma levels contributed to the etiology and how expression affected pain and psychiatric problems related to FMS remains unclear.

The present study, to the best of our knowledge, was the first to demonstrate that patients with the EDN1 TG genotype may have an elevated risk of FMS in the Korean population.
In addition, patients with FMS with the EDN1 T allele exhibited significantly higher plasma EDN1 levels compared with healthy controls. The results revealed that patients with the TG genotype were more susceptible to FMS with increased plasma EDN1 levels. Functional analysis of EDN1 SNP rs1800541 in the future may help to clarify the potential biological mechanism of FMS.

In conclusion, plasma EDN1 levels were significantly increased in Korean patients with FMS compared with those in healthy controls. EDN1 SNP was revealed to be associated with susceptibility to FMS. The power of sample size was calculated using a genetic power calculator (http://zzz.bwh. harvard.edu/gpc). In this study, the genetic power was calculated to be 0.5322 for the EDN1 SNP (number of case: 88 ; control-to-case ratio: 0.988 ; number of cases for $80 \%$ power: 165); it was insufficiently powerful to determine a positive association. Owing to the relatively small number of subjects, these results should be validated by additional studies using larger sample sizes.

\section{References}

1. Mease P: Fibromyalgia syndrome: Review of clinical presentation, pathogenesis, outcome measures, and treatment. J Rheumatol 75: 6-21, 2005.

2. Gran JT: The epidemiology of chronic generalized musculoskeletal pain. Best Pract Res Clin Rheumatol 17: 547-561, 2003.

3. Russell IJ and Larson AA: Neurophysiopathogenesis of fibromyalgia syndrome: A unified hypothesis. Rheum Dis Clin North Am 35: 421-435, 2009.

4. Russell IJ, Orr MD, Littman B, Vipraio GA, Alboukrek B, Michalek JE, Lopez Y and MacKillip F: Elevated cerebrospinal levels of substance $\mathrm{P}$ in patients fibromyalgia syndrome. Arthritis Rheum 37: 1593-1601, 1994.

5. Giovengo SL, Russell IJ and Larson AA: Increased concentrations of nerve growth factor in cerebrospinal fluid of patients with fibromyalgia. J Rheumatol 26: 1564-1569, 1999.

6. Ozgocmen S, Ozyurt H, Sogut S and Akyol H: Current concepts in the pathophysiology of fibromyalgia: The potential role of oxidative stress and nitric oxide. Rheumatol Int 26: 585-597, 2006.

7. Maes M, Libbrecht I, Van Hunsel F, Lin AH, De Clerck L,Stevens W, Kenis G, de Jongh R, Bosmans E and Neels H: The immune-inflammatory pathophysiology of fibromyalgia: Increased serum soluble gp130, the common signal transducer protein of various neurothrophic cytokines. Psychoneuroendocrinology 24: 371-383, 1999.

8. Bondy B, Spaeth M, Offenbaecher M, Glatzeder K, Stratz T, Schwarz M, de Jonge S, Krüger M, Engel RR, Färber L, et al: The T102C polymorphism of the 5-HT2A-receptor gene in fibromyalgia. Neurobiol Dis 6: 433-439, 1999. 
9. Vargas-Alarcón G, Fragoso JM, Cruz-Robles D, Vargas A Vargas A,Lao-Villadóniga JI,García-FructuosoF,Ramos-KuriM, Hernández F, Springall R, et al: Catechol-O-methyltransferase gene haplotypes in Mexican and Spanish patients with fibromyalgia. Arthritis Res Ther 9: R110, 2007.

10. Buskila D, Cohen H, Neumann L and Ebstein RP: An association between fibromyalgia and the dopamine D4 receptor exon III repeat polymorphism and relationship to novelty seeking personality traits. Mol Psychiatr 9: 730-741, 2004.

11. Vane JR, Anggård EE and Botting RM: Regulatory functions of the vascular endothelium. N Engl J Med 323: 27-36, 1990.

12. Schiffrin EL and Thibault G: Plasma endothelin in human essential hypertension. Am J Hypertens 4: 303-308, 1991.

13. Arinami T, Ishikawa M, Inoue A, Yanagisawa M, Masaki T, Yoshida MC and Hamaguchi H: Chromosomal assignments of the human endothelin family genes: The endothelin-1 gene (EDN1) to 6p23-p24, the endothelin-2 gene (EDN2) to 1p34 and the endothelin-3 gene (EDN3) to 20q13.2-q13.3. Am J Hum Genet 48: 990-996, 1991.

14. Pache M, Schwarz HA, Kaiser HJ, Wüest P, Klöti M, Dubler B and Flammer J: Elevated plasma endothelin-1 levels and vascular dysregulation in patients with rheumatoid arthritis. Med Sci Monit 8: CR616-CR619, 2002.

15. Kuryliszyn-Moskal A, Klimiuk PA, Sierakowski S and Ciolkiewicz M: A study on vascular endothelial growth factor and endothelin-1 in patients with extra-articular involvement of rheumatoid arthritis. Clin Rheumatol 25: 314-319, 2006.

16. La Montagna G, Cacciapuoti F, Buono R, Manzella D, Mennillo GA, Arciello A, Valentini G and Paolisso G: Insulin resistance is an independent risk factor for atherosclerosis in rheumatoid arthritis. Diab Vasc Dis Res 4: 130-135, 2007.

17. Stavropoulos-Kalinoglou A, Metsios GS, Koutedakis Y, Nevill AM, Douglas KM, Jamurtas A, van Zanten JJ, Labib M and Kitas GD: Redefining overweight and obesity in rheumatoid arthritis patients. Ann Rheum Dis 66: 1316-1321, 2007.

18. Panoulas VF, Douglas KM, Smith JP, Taffé P, Stavropoulos-Kalinoglous A, Toms TE, Elisaf MS, Nightingale $P$ and Kitas GD: Polymorphisms of the endothelin-1 gene associate with hypertension in patients with rheumatoid arthritis Endothelium 15: 203-212, 2008.

19. Wolfe F, Smythe HA, Yunus MB, Bennett RM, Bombardier C, Goldenberg DL, Tugwell P, Campbell SM, Abeles M, Clark P, et al: The American College of rheumatology 1990 criteria for the classification of fibromyalgia. Report of the multicenter criteria committee. Arthritis Rheum 33: 160-170, 1990.

20. Okifuji A, Turk DC, Sinclair JD, Starz TW and Marcus DA: A standardized manual tender point survey. I. Development and determination of a threshold point for the identification of positive tender points in fibromyalgia syndrome. J Rheumatol 24 377-383, 1997.

21. Kim YA, Lee SS and Park K: Validation of a Korean version of the fibromyalgia impact questionnaire. J Korean Med Sci 17 220-224, 2002

22. Mendoza TR, Wang XS, Cleeland CS, Morrissey M, Johnson BA, Wendt JK and Huber SL: The rapid assessment of fatigue severity in cancer patients: Use of the brief fatigue inventory. Cancer 85: 1186-1196, 1999.

23. Richter P, Werner J, Heerlein A, Kraus A and Sauer H: On the validity of the beck depression inventory. A review. Psychopathology 31: 160-168, 1998.

24. Ware JE Jr and Sherbourne CD: The MOS 36-item short-form health survey (SF-36). I. Conceptual framework and item selection. Med Care 30: 473-483, 1992.

25. Kim JT and Shin DG: A standardization study of State-Trait Anxiety Inventory in Korea. New Med J 21: 1223-1229, 1978.

26. Lee H, Kim HK, Won H, Im J, Kwon JT and Kim HJ: Genetic relationship between an endothelin 1 gene polymorphism and lead-related high blood pressure. Mol Cell Toxicol 12: 111-116, 2016.

27. Bauer V and Sotníková R: Nitric oxide-the endothelium-derived relaxing factor and its role in endothelial functions. Gen Physiol Biophys 29: 319-340, 2010

28. Goodwin AT, Smolenski RT, Gray CC, Jayakumar J, Amrani M and Yacoub MH: Role of endogenous endothelin on coronary reflow after cardioplegic arrest. J Thorac Cardiovasc Surg 122: 1167-1173, 2001.
29. Forbes JM, Jandeleit-Dahm K, Allen TJ, Hewitson TD, Becker GJ and Jones CL: Endothelin and endothelin A/B receptors are increased after ischaemic acute renal failure. Exp Nephrol 9: 309-316, 2001

30. Flammer J, Pache M and Resink T: Vasospasm, its role in the pathogenesis of diseases with particular reference to the eye Prog Retin Eye Res 20: 319-349, 2001.

31. Pache M, Ochs J, Genth E, Mierau R, Kube T and Flammer J: Increased plasma endothelin-1 levels in fibromyalgia syndrome. Rheumatology (Oxford) 42: 493-494, 2003.

32. Kim SK, Kim KS, Lee YS, Park SH and Choe JY: Arterial stiffness and proinflammatory cytokines in fibromyalgia syndrome. Clin Exp Rheumatol 28 (6 Suppl 63): S71-S77, 2010.

33. Bennett RM, Clark SR, Campbell SM, Ingram SB, Burckhardt CS, Nelson DL and Porter JM: Symptoms of Raynaud's syndrome in patients with fibromyalgia. A study utilizing the Nielsen test, digital photoplethysmography and measurements of platelet a2-adrenergic receptors. Arthritis Rheum 34: 264-269, 1991.

34. Lapossy E, Gasser P, Hrycaj P, Dubler B, Samborski W and Muller W: Cold-induced vasospasm in patients with fibromyalgia and chronic low back pain in comparison to healthy subjects. Clin Rheumatol 13: 442-445, 1994.

35. Nelson JB, Chan-Tack K, Hedican SP, Magnuson SR, Opgenorth TJ, Bova GS and Simons JW: Endothelin-1 production and decreased endothelin $B$ receptor expression in advanced prostate cancer. Cancer Res 56: 663-668, 1996.

36. Ahn GY, Butt KI, Jindo T, Yaguchi H, Tsuboi R and Ogawa H: The expression of endothelin-1 and its binding sites in mouse skin increased after ultraviolet B irradiation or local injection of tumor necrosis factor alpha. J Dermatol 25: 78-84, 1998.

37. Druml W, Steltzer H, Waldhäusl W, Lenz K, Hammerle A, Vierhapper H, Gasic S and Wagner OF: Endothelin-1 in adult respiratory distress syndrome. Am Rev Respir Dis 148: 1169-1173, 1993.

38. Voerman HJ, Stehouwer CD, van Kamp GJ, Strack van Schijndel RJ, Groeneveld AB and Thijs LG: Plasma endothelin levels are increased during septic shock. Crit Care Med 20: 1097-1101, 1992.

39. Kidd BL and Urban LA: Mechanisms of inflammatory pain. Br J Anaesth 87: 3-11, 2001.

40. Schaible HG, Ebersberger A and Von Banchet GS: Mechanisms of pain in arthritis. Ann NY Acad Sci 966: 343-354, 2002.

41. Rae GA and Henriques MG: Endothelins in inflammation. In: Pro-Inflammatory and Anti-Inflammatory Peptides. Said S (ed). Marcel Dekker, New York, NY, 163-202, 1998.

42. Miyasaka N, Hirata Y, Ando K, Sato K, Morita H, Shichiri M, Kanno K, Tomita K and Marumo F: Increased production of endothelin-1 in patients with inflammatory arthritides. Arthritis Rheum 35: 397-400, 1992.

43. Savoia $C$ and Schiffrin EL: Inhibition of the renin angiotensin system: Implications for the endothelium. Curr Diab Rep 6: 274-278, 2016.

44. Libby P: Current concepts of the pathogenesis of the acute coronary syndromes. Circulation 104: 365-372, 2001.

45. Blake JG and Ridker PM: Novel clinical markers of vascular wall inflammation. Circ Res 89: 763-771, 2001.

46. Sesso HD, Buring JE, Rifai N, Blake GJ, Gaziano JM and Ridker PM: C-reactive protein and the risk of developing hypertension. JAMA 290: 2945-2951, 2003.

47. Preston RA, Ledford M, Materson BJ, Baltodano NM, Memon A and Alonso A: Effects of severe, uncontrolled hypertension on endothelial activation: soluble vascular cell adhesion molecule-1, soluble intercellular adhesion molecule-1 and von Willebrand factor. J Hypertens 20: 871-877, 2002.

48. Blake GJ, Rifai N, Buring JE and Ridker PM: Blood pressure, C-reactive protein, and risk of future cardiovascular events. Circulation 108: 2993-2999, 2003.

49. Thorand B, Löwel H, Schneider A, Kolb H, Meisinger C, Fröhlich M and Koenig W: C-reactive protein as a predictor for incident diabetes mellitus among middle-aged men: Results from the MONICA Augsburg cohort study, 1984-1998. Arch Intern Med 163: 93-99, 2003. 